\title{
COMPARATIVE TACTICAL ANALYSIS ON THE DEFENSIVE PHASE OF THE REAL MADRID AND FCSB FOOTBALL TEAMS
}

\author{
Ion FRĂȚILĂ ${ }^{1 *}$, Dănuț SMÎDU ${ }^{1}$, Neluța SMÎDU² \\ ${ }^{1}$ National University of Physical Education and Sport, Faculty of Physical Education and Sport, \\ Bucharest, Romania \\ ${ }^{2}$ University of Economic Studies, Bucharest, Romania \\ *Corresponding author: ion.fratila68@yahoo.com
}

https://doi.org/10.35189/dpeskj.2020.59.s.10

\begin{abstract}
The study aimed to identify essential aspects of the technical-tactical organization in the defensive phase between the Spanish football team Real Madrid and the Romanian football team FCSB, as well as to interpret and compare the noticeable differences between them in order to establish a model for the optimisation of training sessions for the Romanian football teams. The research methods used are: bibliographic study method, observation method, comparative analysis method, case study method, statistical and mathematical method, video recording method. In order to check the hypotheses, we used the nonparametric Mann-Whitney U test, setting a significance threshold ( $p$ ) of 0.05. The values obtained by adding the ranks were introduced in the calculation formulas to determine the values of $U 1$ and $U 2$, and subsequently they were compared with the values in the Mann-Whitney table. The obtained results emphasised a significant difference regarding the behavioural organization in the defensive phase, aspects revealed in both a descriptive and quantitative form. The interpretation of the results in terms of scores received by the two teams for all components of the defensive organization phase was rendered by graphs, which highlighted a clear superiority of the Spanish football team Real Madrid over the Romanian FCSB team.
\end{abstract}

Keywords: defensive organization, technical and tactical behaviour, Mann-Whitney U test.

\section{Introduction}

Our exploratory study combined both qualitative and quantitative research, this approach being supported by specialists in the field.

According to Niculescu (2002), the purpose of qualitative research is to bring information, explanations, arguments regarding a studied phenomenon. Mason (2002) adds that it aims to serve as a preliminary investigation in order to define a research area, outline some advanced hypotheses and understand the mechanisms governing it, the essential objective not being the discovery of causes, but the way of expressing the behaviours under investigation.

The information collected in qualitative research is not subject to statistical rules, the clarification of the research topic not involving inferential statistical procedures for verifying statistical hypotheses (Popa, 2008), although, in the opinion of Bîrsan (2012), it can be converted into quantitative expressions by codification and can be processed, counted and compared to find out the frequency. According to Duşa (2014), for a better understanding of the expression of a phenomenon, it is necessary to study that phenomenon by qualitative means (observation, case study), and then by quantitative methods.

Mason (2002) states that qualitative research should not be seen in opposition to quantitative research, but complementary to it. Qualitative research is not at all inferior to quantitative research, given that it involves methodological rigor, data collection techniques, 
interpretation methods and valuable research, having as criteria the argumentation of choices, the establishment and specification of the limits of reliability and validity.

The exploratory study involved in the technical-tactical analysis of some "top" teams of Europe has started from the premise that the technical-tactical component, represented by behaviours, organization way, tactical conception of the play, aspects of collective relations, forms, actions that are established between players, all this taken as a whole, are defining, essential, decisive in the qualitative evolution, in obtaining performance, aspects that make the difference among the value levels of the football teams.

This premise was generated by aspects observed in some football teams which, although they had good physical and technical training, recorded mediocre results mainly due to the lack of organization from a tactical point of view.

At the same time, based on the analysis of bibliographic materials, we can say that a quantitative analysis is limited in terms of its validity, thus, only few statistical data providing a significant correlation with the result of a match. To this end, we can give as an example a common predictor, namely, the percentage of possession during a game, which does not correlate with the result of the game, the number of passes or their percentage of accuracy which, identically, have weak correlations with the result (Hughes \& Franks, 2005).

Other essential aspects related to the behaviour and technical-tactical organization of a team, which make a difference in terms of value in the modern football game, are the "transition phases", in which intercepting the pass and triggering the counterattack are key components, which have proven to have a significant correlation in obtaining positive results (Frencken et al., 2012; Turner \& Sayers, 2010; Tenga et al., 2010; McGarry, 2009).

Active pressing, positioning of players in relation to opponents the structural and functional "block", in which the distances between players both horizontally, and vertically (Pulling et al., 2013; Szczepanski, 2008) are determining factors for a superior defensive organization.

The analysis of the tactical aspects of the game from the perspective of using qualitative observation tools is very little known (Gréhaigne et al., 2001), focusing on these means can lead to a better understanding of the association between sports behaviour and results (McGarry, 2009), all having as final point the development of high-performance theoretical and practical models (Sarmento et al., 2014), which should provide the possibility of increasing performance in the football game to the specialists in the field.

Also, the collective tactical organization, the study of behaviour in terms of correlation between the different distances established by players from the team centre (Aguiar et al., 2012) revealed the importance of the tactical factor, of behavioural organization, which can lead to opening new research topics in this field. Our study, conducted through a comparative analysis between a valuable European football team and a $1^{\text {st }}$ League team, aims to explore, to identify the essential, defining and constant aspects of behaviour and organization from the technical-tactical point of view, to bring pertinent information related to the studied phenomenon, to describe, to undertake an analysis and a diagnosis explained in a substantiated manner, in relation to this problem.

The hypothesis of the formulated research is that: there is a significant difference in terms of technical-tactical behaviour at the defensive level between the Spanish football team Real Madrid and the $1^{\text {st }}$ League team of the Romanian championship, FCSB. 


\section{Methodology}

The methods used in the exploratory research are represented by: bibliographic study method, observation method, case study method, modelling method, comparative analysis method, statistical-mathematical method, video recording method.

The research was based on the observation of the organization of the two teams at the defensive level while playing 20 matches each, both in championship, and in international competitions, matches played between August 2018 - January 2020.

The analysis of the matches was carried out by video recording, a way that could ensure stopping and running the game phases to make "screenshots" of the recordings, sketches in graphical form, which could lead to the identification and description of the research aspects in a detailed and substantiated perspective.

The results obtained were collected in registration sheets, each studied match having a specific case assigned. The registration sheet contained elements of analysis with information on the defensive organization of each team, during the 20 matches played.

Taking into account that the technical-tactical organization of a team is the expression of behavioural manifestations at the collective level, we tried in our analysis to point out these aspects in the context of unitary, coordinated relations of the players taken as a whole, not individually (Gréhaigne et al., 1997).

In this approach, to accompany the descriptive analysis and graphically "score" the essential aspects, we used two applications: "football tactics.net" and "tactical-board", and, for a more solid analysis and wanting to render faithfully and to argument personal opinions and views, we used the "Snagit 5.0" software for screenshots.

So, in order for the descriptive aspects of the exploratory research of the technical-tactical behaviour to be subject to the verification of hypotheses and the rigor of statistical calculations, they needed a transformation from the area of qualitative, descriptive data to that of quantitative, numerical data. To this end, we developed a numerical scoring system with scales from 1 to 4, each scale being assigned a rating (insufficient, sufficient, good, very good) to express a certain technical-tactical behaviour present in the defence phase.

\section{Results}

For a better understanding, the research results were presented in both a descriptive and graphical form (Tables 1-3 and Figure 1).

Table 1. Scores for tactical behaviour obtained by the Real Madrid team in the defence phase

\begin{tabular}{lcccccc}
\hline Match & Loss of possession & Retreat & Organized defence & Transition & Free kicks & Corners \\
\hline 1. & 3 & 3 & 3 & 2 & 4 & 3 \\
2. & 3 & 2 & 2 & 2 & 3 & 2 \\
3. & 4 & 4 & 4 & 4 & 4 & 3 \\
4 & 3 & 3 & 2 & 3 & 3 & 1 \\
5 & 4 & 4 & 4 & 4 & 4 & 3 \\
6. & 4 & 3 & 4 & 3 & 4 & 3 \\
7. & 4 & 3 & 3 & 4 & 4 & 3 \\
8. & 4 & 4 & 4 & & 4
\end{tabular}


Discobolul - Physical Education, Sport and Kinetotherapy Journal, Volume 59, Supplementary Issue, 592-601

\begin{tabular}{lcccccc}
9. & 3 & 3 & 3 & 4 & 3 & 2 \\
10. & 3 & 2 & 2 & 3 & 3 & 3 \\
11. & 3 & 3 & 3 & 4 & 3 & 2 \\
12. & 2 & 2 & 2 & 2 & 4 & 4 \\
13. & 4 & 4 & 4 & 4 & 3 & 4 \\
14. & 4 & 4 & 4 & 4 & 4 & 3 \\
15. & 3 & 3 & 3 & 3 & 4 & 3 \\
16 & 4 & 4 & 4 & 4 & 4 & 3 \\
17. & 4 & 4 & 4 & 4 & 4 & 3 \\
18. & 3 & 3 & 2 & 3 & 3 & 3 \\
19. & 4 & 4 & 4 & 4 & 4 & 4 \\
20. & 3 & 3 & 3 & 3 & 3 & 3 \\
Amount & 69 & 65 & 64 & 68 & 71 & 59 \\
Minimum & 2 & 2 & 2 & 2 & 3 & 1 \\
Maximum & 4 & 4 & 4.2 & 3.4 & 3.55 & 2.95 \\
Mean & 3.45 & 3.25 & 0.73 & 0.75 & 0.51 & 0.75 \\
STDEV & 0.61 & 0.73 & 25.05 & 14.36 & 25.42 \\
CV & 17.68 & 22.46 & 25.93 & & & \\
\hline
\end{tabular}

Table 2. Scores for tactical behaviour obtained by the FCSB team in the defence phase

\begin{tabular}{lcccccc}
\hline \multicolumn{1}{c}{ Match } & Loss of possession & Retreat & Organized defence & Transition & Free kicks & Corners \\
\hline 1. & 2 & 2 & 2 & 2 & 3 & 2 \\
2. & 2 & 2 & 2 & 2 & 2 & 3 \\
3. & 2 & 2 & 2 & 2 & 3 & 3 \\
4 & 3 & 3 & 2 & 2 & 3 & 3 \\
5 & 2 & 2 & 2 & 2 & 1 & 3 \\
6. & 2 & 2 & 2 & 2 & 3 & 3 \\
7. & 2 & 2 & 3 & 3 & 1 & 3 \\
8. & 3 & 3 & 2 & 3 & 3 & 2 \\
9. & 2 & 2 & 1 & 2 & 2 & 2 \\
10. & 3 & 3 & 2 & 2 & 3 & 3 \\
11. & 2 & 2 & 1 & 2 & 2 & 3 \\
12. & 3 & 3 & 3 & 3 & 3 & 2 \\
13. & 2 & 2 & 2 & 2 & 1 & 3 \\
14. & 3 & 3 & 3 & 3 & 3 & 3 \\
15. & 1 & 1 & 2 & 1 & 1 & 2 \\
16 & 2 & 2 & 1 & 2 & 2 & 1 \\
17. & 3 & 3 & 2 & 2 & 3 & 3 \\
18. & 2 & 2 & 1 & 2 & 2 & 1 \\
19. & 3 & 3 & 3 & 3 & 3 & 3 \\
20. & 3 & 3 & 4 & 3 & 3 & 3 \\
Amount & 47 & 47 & 42 & 45 & 47 & 51 \\
Minimum & 1 & 1 & 1 & 1 & 1 & 1 \\
Maximum & 3 & 3 & 4 & 3 & 3 & 3 \\
Mean & 2.35 & 2.35 & 2.10 & 2.25 & 2.35 & 2.55 \\
STDEV & 0.59 & 0.58 & 0.78 & 0.56 & 0.81 & 0.69 \\
CV & 9.56 & 9.4 & 14 & 9.47 & 13 & 10 \\
\hline
\end{tabular}




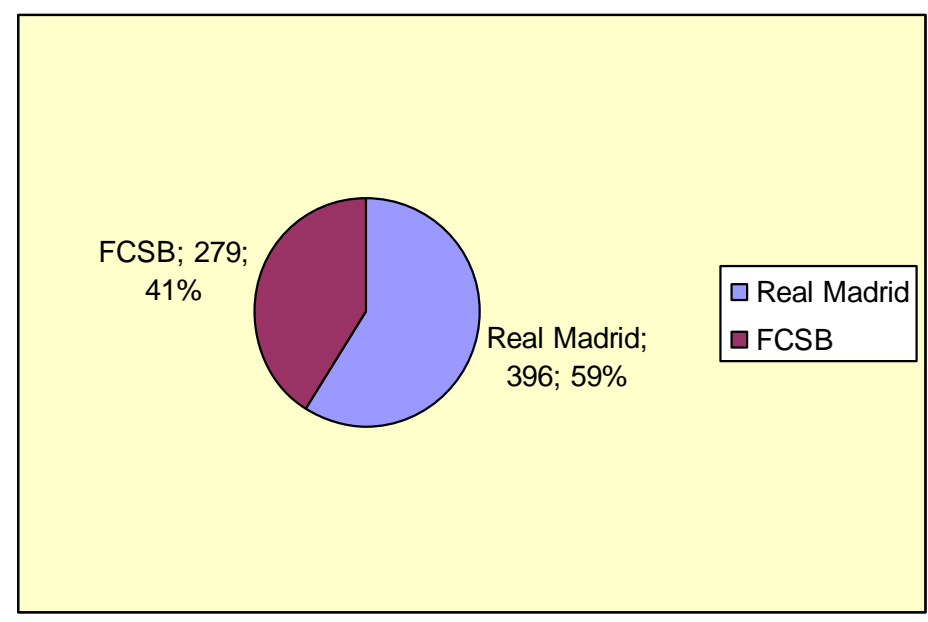

Figure 1. Total amount and percentage scores in the defensive phase for the Real Madrid and FCSB football teams

Table 3. Mann-Whitney U test values

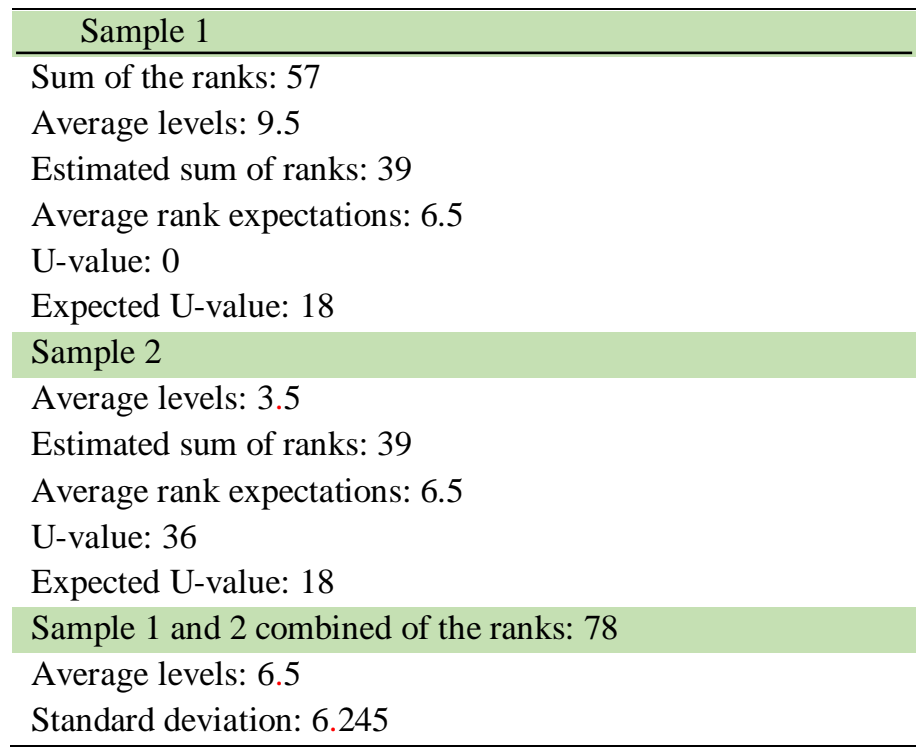

By studying the graph with the scores allocated for each manifested technical-tactical behaviour, one can observe the clear superiority of the Real Madrid football team over the Romanian FCSB team.

The big differences highlighted in all the components of the defensive phase confirm the descriptive aspects researched by us, they explain the nature and inconsistency of the results, of the value between the two teams.

As regards the analysis of the spread indices, it can be seen that the standard deviation is within normal limits, and in terms of coefficient of variation, the indices confirm a good degree of spread and therefore an average that is sufficiently representative.

In order to verify our hypothesis that there is a significant difference between the Real Madrid and FCSB football teams in terms of defensive behaviour, we chose the nonparametric Mann-Whitney $U$ test, establishing a significance threshold (p) of 0.05. The 
values resulting from the addition of the ranks were introduced in calculation formulas in order to establish the values of U1 and U2.

In order to reject the "null hypothesis", we calculated the values, and they were confronted with the values of $U$ from the table, and the results support our hypothesis that there is a significant difference between the two teams in terms of defensive technical-tactical behaviour.

Regarding the descriptive analysis of the defensive organization of the Real Madrid football team, we can deduce the following constants:

The playing system that was mostly used during the analysed matches was "1-4-3-3", system which, sometimes while playing, or in other matches, according to the opponents' actions and features, the validity of the team or other situational variables, becomes, in the defence phase, “1-4-5-1", “1-4-2-3-1", "1-4-4-2”, “1-4-1-4-1".

After losing the possession of the ball, regardless of the area, the Real Madrid players, who are permanently organized, coordinate their actions to recover it as soon as possible.

Most of the players are involved in the action of recovering the ball, the pressing being adapted according to the area of the field and the opponent's position.

The efficiency of the pressing is given by the players' intelligent positioning, by the small distances among them, which allow them to encircle the opponent with the ball in any area of the field.

The players who are closest to the opponent with the ball (two or three players) make a pressing oriented to the man and the space around him, the other players, from the second pressing line, executing a close man marking, the opponent with the ball is encircled by three, four players, who block his lanes of pass for his teammates.

When the construction starts from the opposing goalkeeper, the Real Madrid players use pressing schemes aiming either at the goalkeeper's kicking away the ball and then the recovery of the ball due to the qualities of the defensive compartment or the orientation of the passes in the central or lateral axis.

When the aim is that the ball should be kicked away by the opposing goalkeeper, the centre forward marks the goalkeeper, and the wings mark the centre-backs. The pressing is launched by all means in the following situations: the opponent's pass to the goalkeeper, passes between centre-backs or any pass in the lateral positions of the field.

If the triggered pressing does not lead to the recovery of the ball, then the players withdraw in a coordinated way to the defensive positions, trying to keep the defenders' line as high as possible and to apply the "play in offside position".

In the defensive organization phase, we notice that the players have a good structure and dynamic materialised in small distances between the compartments, allowing optimal coverage of the vulnerable areas, a good translational movement in the lateral and horizontal axis, exchange of places when the defender/back leaves to mark the opposing player positioned between the lines, blocking the passing or shooting lanes, isolating the player with the ball, providing numerical superiority, anticipating the opponents' actions and counteracting them, while adapting their own actions and applying structural and functional changes. Concerning the negative transaction phase, we can notice that the players, after losing possession, participate in the actions of quick recovery of the ball in a coordinated and organized manner. 
The analysed fixed phases, especially the free kicks and corners, revealed the players' good positioning, the choice of a good structure at the free kicks and, as regards the corners, a good organization, approach and interpretation of the phases.

The analysis of the played matches allowed us to outline some ways of technical-tactical behaviour frequently applied in this phase. Thus, in most of the matches, the players use a mixed defence system on two lines at corner kicks, made up of four players positioned in front of the six-meter square, squared on the goal area, applying a zonal marking, and three or four players making a "man-to-man" marking.

In order to block a possible pass at the ground level or to prevent a combination of the opposing executor of the corner kick with another teammate, a player is usually placed 9 meters from the corner line of the field, and a player located outside the 16-meter square ensures its reception if it is rejected by teammates or opponents.

The positive aspects of our analysis revealed a small number of mistakes in the defence phase, having, as a starting point, individual, not collective mistakes, which were corrected, most of the times, by collective actions, thus the defensive system rarely being disorganized.

In all the defensive phases, one can notice a good organization materialised in appropriate positioning and placement, optimum coordination and dynamic of the players, vertical and horizontal axis distances providing an optimal "functional block", choosing the best ways to block the opponent, closing the penetration spaces and corridors.

The procedures used to counteract the opponents' actions are adapted to the requirements imposed by the context, chosen and executed at high parameters.

Concerning the negative points in the defensive organization of the Real Madrid team, which were noticed during the analysis of the matches allocated to the research, we can discover three major weak points:

As the central defenders' line is positioned very high, and the defenders actively participate in the attack phase, the team is caught when it loses the possession when employing over the centre-back line or on the free side as a result of the backs' climbing.

Another negative aspect is the players' poor positioning, the misinterpretation of the opponents' actions at the corners, especially when the Real players make a "man-to-man" mark and, from outside the square, an opposing player who is not marked launches himself, as well as at the balls deviated by the opponent for another teammate.

Another minus is given by the poor positioning of the midfield line at the opponent' crosses executed in front of the defenders who leave a large space between them and allow the use of the free space by the opponent and the completion of the action.

As regards the defensive organization of the FCSB team, we can discern the following patterns: the most common playing systems used in the analysis of the matches played by the FCSB team were 1-4-2-3-1 and 1-4-3-3.

After losing possession of the ball, the player who is closest to the opponent with the ball performs an action of marking, of preventing the transmission of the ball, which, unfortunately, fails most of the times, because this isolated action, not being accompanied by a collective action of the FCSB team players, who withdraw quickly on defensive positions, contribute to reduced efficiency in ball recovery. This approach creates a big gap between the line of the centre forwards and the one of the defenders/backs, spaces used by the opponent in most of the cases. 
In the 1-4-2-3-1 system, we noticed mistakes of interpretation at the closing midfields who perform the translational movement covering the area where the player with the ball is, but leave a huge space on the left side, which is appropriately used by the opponent. In this case, the full back is numerically inferior and, regardless of the solution chosen (either to go out to meet the player or to remain in a defensive position), the player is counteracted.

Another frequently noticed mistake, this time the team being arranged in a 1-4-3-3 system, is that the midfields are positioned in line, and the opponents in a "diamond" arrangement create both superiority at the centre of the field, and multiple possibilities of progression.

This imbalance among the distances among the players from the compartments attracts opportunities for the opponent, the opposing team having a clear superiority in the central area, which ensures it a multitude of completion options.

This arrangement in line of the players, and the large distances between the midfield compartment and the defenders' compartment make it impossible to mark the opposing player demarcated between the lines.

The huge distances between compartments are the cause, in most of the analysed matches, of opportunities for the progression of the opponents.

We could notice in many matches that the defensive organization has big problems, as it does not provide numerical superiority in this phase, the centre-backs being caught in numerical inferiority or in which the midfield compartment is arranged in advanced positions, leaving large spaces for the opponents.

We also noticed mistakes in players' positioning, which allowed the opponent to remain unmarked and to centre.

In the negative transition phase, we can conclude that the FCSB players, although they isolate the opposing ball carrier, this action is not accompanied in many cases by coordinated collective actions, the back compartment withdraws quickly without being accompanied by a coordinated withdrawal of the midfield, which is reflected in the creation of huge spaces between the lines.

As regards the fixed phases, we can notice a good organization in the way of approaching these phases.

Concerning some positive aspects of the defensive approach of the FCSB players' behaviour, one can notice that, in important matches, respectively the qualification phases in the European League, the team had good performance, and the mistakes were corrected by a good collective participation.

Regarding the negative aspects, we can conclude that the players, during the analysed matches, make a lot of interpretation and positioning mistakes. The team is disorganized, with large spaces between compartments, it does not withdraw in a coordinated manner, and the specific organizational automations are missing.

At the fixed phases, we noticed a good organization, the team being rarely caught at such phases. 


\section{Conclusion}

Following the analysis of the data, of the acquired information and of their interpretation, both from a descriptive, and a statistical point of view, we can draw some conclusions:

As regards the technical-tactical behaviour of the Real Madrid football team, we can notice a remarkable organization in the defensive phase.

The small distances among the players allow a good progression both in the attack phase, and in the defensive phase, which contributes to a quick isolation of the opponent and to the creation of numerical superiority.

The Real Madrid team is vulnerable to the counterattacks of the opponents who use the employment of the teammates on the side lines or over the back line, which is placed up and at the corner kicks, when the choice of the marking methods is wrong sometimes, but these mistakes are few and are corrected to a large extent.

In conclusion, we can state that the Real Madrid football team is organized at a high level, is based on a modern play seeking, when in attack, to place its players so as to recover the ball quickly in case of losing possession.

Concerning the FCSB football team, following the analysis of the matches allocated to the research, we could notice that, when the team meets opponents making an aggressive pressing, they do not have construction solutions, the players are wrongly positioned, slow, predictable, sometimes static, they do not use passes with one or two touches, they do not coordinate their actions, they do not contribute by an active demarcation to support the player with the ball and to provide passing options.

Due to the players' wide positioning, to the gap between the back compartment and forward compartment, the pressing action after the loss of the possession is not efficient, that is why, in most of the matches, it was used, as a marking form, the zonal marking, which was challenged by the opponent by creating numerical superiority on the free spaces.

A great vulnerability was noticed on the sides of the enclosures when the team used a 1-42-3-1 playing system, as the players had a slow translation movement to the opponents' quick changes of directions.

Also, due to the large distances among players, the team was vulnerable to the opponents' play between the lines, and the positioning in line of the midfields in the 1-4-3-3 system led to obtaining the opponent's superiority in the central area.

As regards the fixed phases, we notice a good organization in both the attack phase and the defence phase, which allows us to promote the idea that these phases are well exercised in the training sessions.

In conclusion, we can state that the FCSB football team bases its play on the players' individual talent and value, and not on a summed, collective value. We could notice many mistakes in the analysed matches, which have, as a starting point, a poor organization of the defence phase from a technical and tactical point of view. 


\section{References}

Aguiar, M., Botelho, G., Lago, C., Maças, V., \& Sampaio, J. (2012). A review on the effects of soccer small-sided games. Journal of Human Kinetics, 33, 103-113. https://doi.org/10.2478/v10078-012-0049-x

Bîrsan, M. (2012). Metodologia cercetării. Note de curs [Research methodology. Course notes]. București.

Duşa, A. (2014). Elemente de analiză comparativă [Elements of comparative analysis]. București: Tritonic.

Frencken, W., de Poel, H., Visscher, C., \& Lemmink, K. (2012). Variability of inter-team distances associated with match events in elite-standard soccer. Journal of Sports Sciences, 30(12), 1207-1213. https://doi.org/10.1080/02640414.2012.703783

Gréhaigne, J.-F., Bouthier, D., \& David, B. (1997). Dynamic-system analysis of opponent relationships in collective actions in soccer. Journal of Sports Sciences, 15(2), 137-149. https://doi.org/10.1080/026404197367416

Gréhaigne, J.-F., Godbout, F., \& Bouthier, D. (2001). The teaching and learning of decision making in team sport. Quest, 53(1), 59-76. https://doi.org/10.1080/00336297.2001.10491730

Hughes, M., \& Franks, I. (2005). Analysis of passing sequences, shots and goals in soccer. Journal of Sports Sciences, 23(5), 509-514. https://doi.org/10.1080/02640410410001716779

Mason, J. (2002). Qualitative researching. London: Sage.

McGarry, T. (2009). Applied and theoretical perspectives of performance analysis in sport: Scientific issues and challenges. International Journal of Performance Analysis in Sport, 9(1), 128-140. https://doi.org/10.1080/24748668.2009.11868469

Niculescu, M. (2002). Metodologia cercetării științifice în educație fizică și sport [Scientific research methodology in physical education and sports]. București: Bren.

Popa, M. (2008). Statistică psihologică și prelucrarea datelor [Psychological statistics and data processing]. Iași: Polirom.

Pulling, C., Matthew, R., \& Rixon, T. (2013). Defending corner kicks: Analysis from the English Premier League. International Journal of Performance Analysis in Sport, 13(1), 135-148. https://doi.org/10.1080/24748668.2013.11868637

Sarmento, H., Marcelino, R., Anguera, M. T., Campaniço, J., Matos. N., \& Leitão, J. C. (2014). Match analysis in football: A systematic review. Journal of Sports Sciences, 32(20), 1831-1843. https://doi.org/10.1080/02640414.2014.898852

Szczepanski, L. (2008). Measuring the effectiveness of strategies and quantifying player' performance in football. International Journal of Performance Analysis in Sport, 8(2), 5566. DOI: $10.1080 / 24748668.2008 .11868435$

Turner, B. J., \& Sayers, M. G. L. (2010). The influence of transition speed on event outcomes in a high-performance football team. International Journal of Performance Analysis in Sport, 10(3), 207-220. https://doi.org/10.1080/24748668.2010.11868516

Tenga, A., Holme, L., Ronglan, T., \& Bahr, R. (2010). Effect of playing tactics on goal scoring in Norwegian professional soccer. Journal of Sports Sciences, 28(3), 237-244. https://doi.org/10.1080/02640410903502774 